Jurnal Ilmiah Mahasiswa Kendali dan Listrik
Vol. xx, No. xx, Mounth 2020, page-page. $\mathbf{x} \sim \mathbf{x x}$
E-ISSN: 2723-598X
DOI: https://doi.org/10.33365/jimel.v1i1

\title{
RANCANG BANGUN SISTEM CERDAS TERPUSAT UNTUK LOKASI PARKIR MENGGUNAKAN TCRT5000 BERBASIS ARDUINO
}

\author{
Abet Nego Adi S. ${ }^{1}$, Noza Pratama ${ }^{2}$, Agong Chaniago ${ }^{3}$, S.Samsugi ${ }^{4}$ \\ ${ }^{1}$ Program Studi D3 Teknik Komputer Fakultas Teknik Dan Ilmu Komputer, Universitas Teknokrat Indonesia \\ ${ }^{2}$ Program Studi S1 Teknik Komputer Fakultas Teknik Dan Ilmu Komputer, Universitas Teknokrat Indonesia \\ ${ }^{3,4}$ Program Studi S1 Teknik Elektro Fakultas Teknik Dan Ilmu Komputer, Universitas Teknokrat Indonesia
}

Abet.nego@gmail.com,nozapratam@gmail.com, agong.chaniago@gmail.com, s.samsugi@teknokrat.ac.id

\begin{tabular}{lll}
\hline Received: (date month year) & Accepted: (date month year) & Published : (date month year) \\
\hline
\end{tabular}

Abstract

This parking system simulation aims to design a system to make it easier for parking users to park vehicles and vehicle safety. The working system in this parking simulation works with an Arduino Mega 2560 R3 microcontroller chip as the main processor that controls all components. Another device, namely 1 ultrasonic sensor for vehicle detection sensors at the entrance and 1 sensor at the exit. Next, the rc522 frid module is also used as an electronic ticket so that vehicle security is maintained and also as a parking entrance key that functions to open a parking portal using a servo motor. And for the condition of notifying the location of an empty or full parking area, several sensors are also installed in each parking lot slot so that the system can monitor the condition of the vehicle at the parking lot location by displaying it on an LCD monitor.

Keywords: Smart's Parking System, Radio Frequency and Identification (RFID), Arduino

\begin{abstract}
Abstrak
Simulasi sistem parkir ini bertujuan untuk merancang sebuah sistem dalam memudahkan pengguna parkir dalam memarkirkan kendaraan dan keamanan kendaraan. Sistem kerja pada simulasi parkir ini bekerja dengan sebuah chip mikrokontroller arduino mega 2560 R3 sebagai pemroses utama yang mengontrol semua komponen. Perangkat lain yaitu 1 buah sensor ultrasonic untuk sensor pendeteksi kendaraan dipintu masuk dan 1 buah sensor di pintu keluar. Berikutnya digunakan juga module frid rc522 sebagai tiket elektronik agar keamanan kendaraan tetap terjaga dan juga sebagai kunci pintu masuk parkir yang berfungsi membuka portal parkir yang menggunakan motor servo. Dan untuk kondisi memberitahukan letak lahan parkir kosong atau penuh dipasang juga beberapa sensor disetiap slot-slot lahan parkir sehingga sistem bisa memonitoring kondisi kendaraan pada lokasi lahan parkir dengan menampikan ke lcd monitor.
\end{abstract}

Kata Kunci : Smart's Parking Sistem, Radio Frequency and Identification (RFID), Arduino

To cite this article:

Authors. (Year). Title of the article. Jurnal Ilmiah Mahasiswa Kendali dan Listrik, Vol(1), Page-Page.

\section{T. PENDAHULUAN}


Saat ini ketersediaan lahan parkir telah menjadi suatu kebutuhan yang penting bagi masyarakat. Dengan banyaknya jumlah kendaraan karena ketergantungan manusia pada sarana transportasi khususnya mobil semakin bertambah besar untuk menunjang kegiatan sehari-hari, tentunya membutuhkan tempat parkir yang bertambah luas terutama pada Universitas atau Perkantoran. Sistem parkir yang ada saat ini tidak mendukung kebutuhan pengendara yang hanya memanfaatkan lahan parkir dan petugas parkir yang mengendalikan tiap-tiap kendaraan yang masuk, dan juga sering kali tidak memperhatikan daya tampung dari lahan parkir yang dimiliki. Masalah yang ditimbulkan dalam sistem perparkiran adalah kurangnya informasi mengenai lahan parkir yang kosong serta penempatan kendaraan yang tidak sesuai sehingga sering kali pemilik kendaraan membutuhkan waktu yang lama untuk sekedar menemukan tempat parkir yang kosong [1]. Sistem parkir manual pada pelayanan parkir mall memerlukan pengelolaan dan pengembangan sistem yang lebih rumit dan jauh dari kata efisien. Informasi yang didapatkan pengelola parkir terkait kondisi parker di lapangan setiap harinya masih kurang [2]. Sistem parkir manual dengan ratusan bahkan mungkin ribuan kendaraan bermotor memerlukan pengawasan yang ekstra ketat karena dengan ribuan kendaraan bermotor [3]. Waktu yang lama saat pencatatan pelat nomor kendaraan secara manual di sistem parkir menimbulkan antrean. Penelitian ini mengembangkan sistem parkir otomatis berbasis RFID dan pengolahan citra pelat nomor kendaraan [4]. Problem perparkiran kadang merupakan hal yang krusial untuk di cari solusinya agar dapat memberikan kepraktisan, keamanan dan kenyamanan bagi pengemudi kendaraan serta efisiensi penggunaan lahan parkir yang serba terbatas. Banyak waktu terbuang dan kadang cukup merepotkan hanya untuk mencari tempat parkir pada jam sibuk [5]. Dari permasalahan diatas, muncul ide untuk membuat peralatan elektronik yang bekerja secara otomatis untuk dapat diterapkan pada tempat parkir khususnya untuk kendaraan mobil yakni Rancang Bangun Prototipe Sistem Cerdas Perparkiran Mobil Menggunakan TCRT5000 Berbasis Arduino Dengan Kendali Terpusat..

\section{TELAAH PUSTAKA}

Untuk mempermudah dalam parkir mobil agar efisien dibuthkan alat pemandu parkir dengan memperlihatkan jarak dengan benda disekitar [6]. Beberapa penelitian terkait dengan pembuatan system parker diantaranya Pembuatan sistem parkir dengan RFID, Dengan adanya penggunaan RFID untuk sistem parkir, diharapkan dapat membuat sistem parkir yang ada di Unikom saat ini dapat berjalan lebih baik, aman dan nyaman.[7]. Tujuan penelitian yang dilakukan adalah merancang dan merealisasikan model sistem monitoring perparkiran dengan fasilitas pemilihan area parkir dengan berbasiskan Raspberry Pi serta pemanfaatan infrared sebagai sensor. Sistem ini mampu menampilkan status ketersediaan dari area parkir yang ditampilkan pada display serta dilengkapi dengan perhitungan tarif parkir. Pada sistem yang dirancang dilengkapi dengan tombol untuk memilih area parkir, 2 buah sensor pada masing-masing area parkir untuk mendeteksi kendaraan, kamera untuk kemanan dan lampu LED sebagai indikator ketersediaan area parker [8]. Untuk merancang system parker di butuhkan beberapa perangkat di antaranya:

1. Arduino Uno sebagai pemroses

Arduino UNO merupakan board Arduino revisi terbaru yang merupakan penerus dari Arduino Duemilanove. Yang membedakan antara arduino uno dan arduino duemilanove yaitu tidak lagi digunakannya chip FTDI (USB to Serial driver) dan sebagai gantinya menggunakan Atmega8U2 yang diprogramkan untuk berfungsi sebagai konverter USB-toSerial [9].

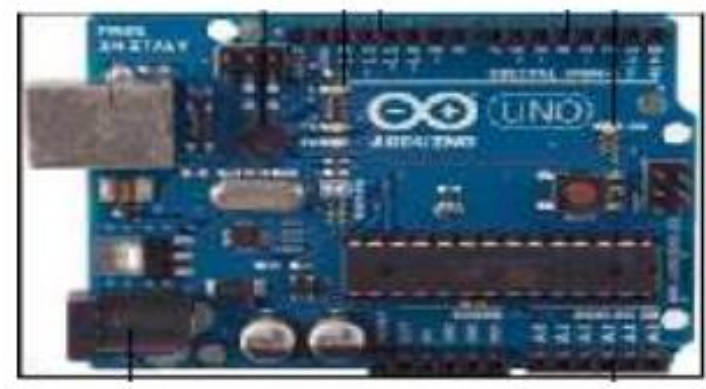

Gambar 1 Arduino Uno

2. Sensor TCRT5000 
Sensor pendeteksi garis sebenarnya bisa dibuat dengan menggunakan LED, LDR, dan komparator untuk mengambil keputusan adanya garis atau tidak. Namun, untuk mempermudah implementasi, modul yang ditujukan untuk mendeteksi garis bisa menjadi pilihan. Salah satu modul untuk mendeteksi garis dinamakan IR line tracking sensor TCR5000 YL-54 [10].

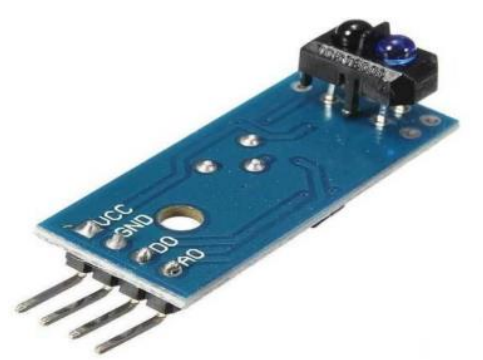

Gambar 2 Sensor Infra Merah

3. RFID Card/TAG adalah sebuah TAG RFID atau Transponder, terdiri atas sebuah microchip dan sebuah antena. Chip tersebut menyimpan nomor seri yang unik/ID dan informasi lainnya tergantung kepada tipe memorinya. Tipe memori itu sendiri dapat diread-only, readwrite, atau write-onceread-many. Antena yang terpasang pada microchip mengirimkan infomasi ke reader RFID.

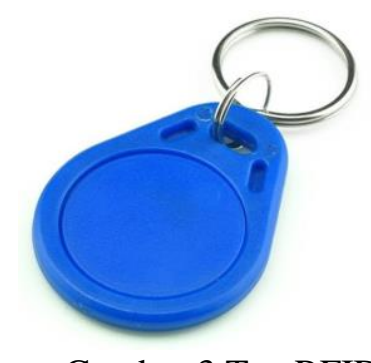

Gambar 3 Tag RFID

4. Motor Servo

Motor servo merupakan salah satu jenis dari motor DC dan banyak diaplikasikan pada dunia robotik maupun peralatan lain, contohnya motor servo yang digunakan untuk robot berkaki [11]. Dalam penggunaannya motor servo dapat bergerak karena ada sinyal yang dibangkitkan melalui sinyal PWM [12].

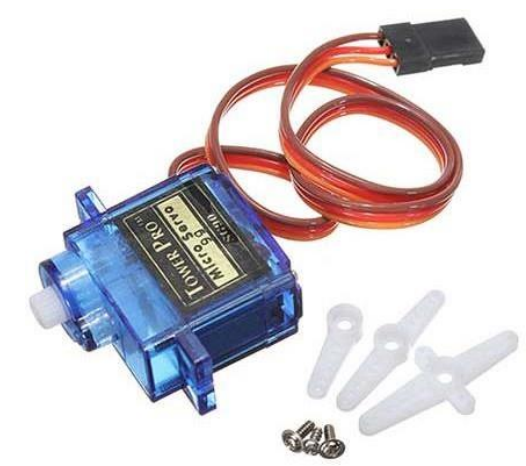

Gambar 4 Motor Servo 
Perancangan alat adalah suatu metode awal dalam pembuatan sebuah alat yang sangat penting karena tanpa sebuah perancangan alat yang dibuat tidak dapat berjalan dengan maksimal. Untuk memperoleh hasil yang maksimal diperluhkan rancangan yang baik dengan memperhatikan sifat dan karakteristik dari tiap-tiap komponen yang digunakan, agar kerusakan komponen dapat dihindari. Dalam tahap perancangan terdiri beberapa tahapan yaitu perancangan diagram blok, diagram alir atau flowchat, alat dan bahan, hingga pada perancangan keseluruhan alat. Perancangan memerluhkan suatu ketelitian, keuletan dan ketepatan karena perancangan awal akan menentukan akhir dari suatu perancangan dalam proses pembuatan alat. Jika perancangan awal salah maka hasil akhirnya akan salah. Proses perancangan sangat diperluhkan dalam proses pembuatan alat, khususnya perancangan alat elektronika. Perancangan rangkaian keseluruhan alat terdiri dari empat elemen penting yang saling terintegrasi. Elemen-elemen penting tersebut yaitu rangkaian input, rangkaian pengendali, rangkaian output dan juga software program yang saling terintegrasikan. Rangkaian yang terdiri komponenkomponen elektronika baik berupa input atau output yang dibutuhkan oleh mikrokontroller agar dapat berfungsi dengan baik. Rangkaian keseluruhan alat dapat dilihat pada gambar 5 .

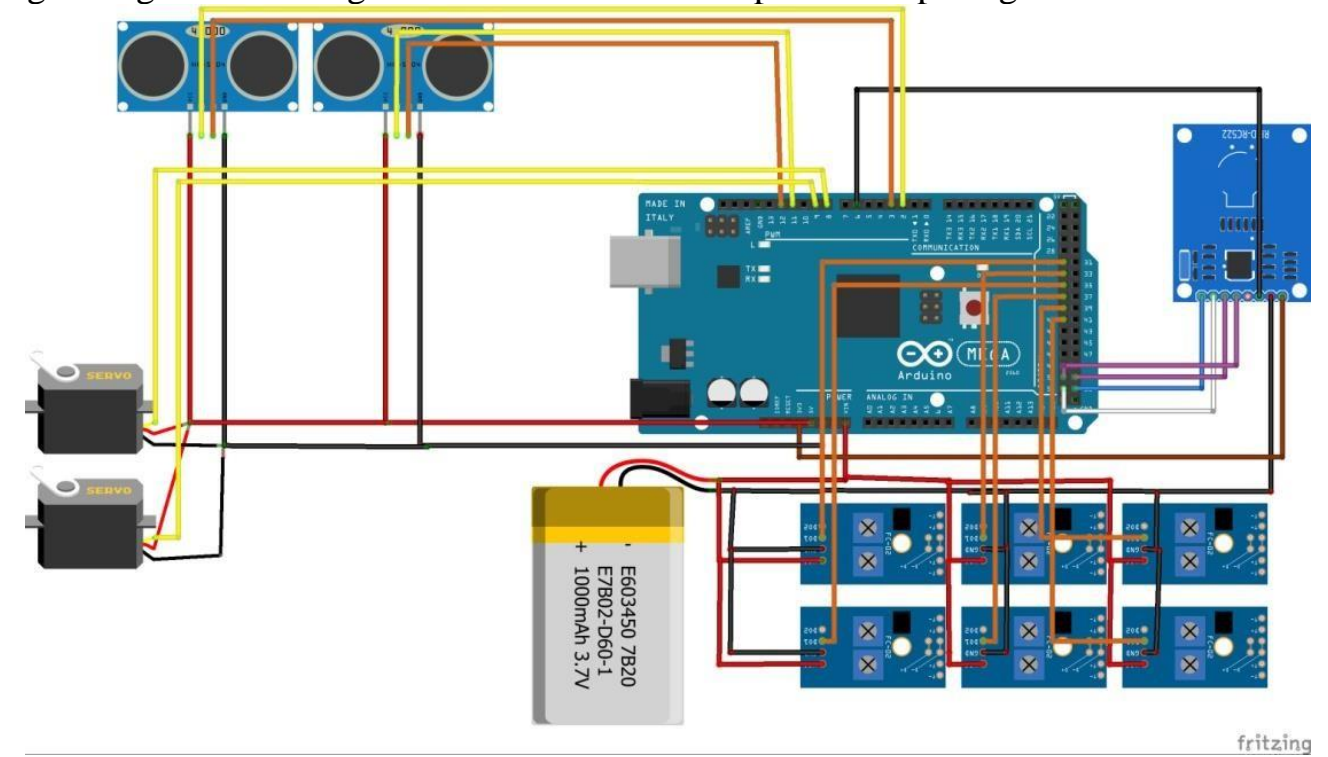

Gambar 5 Rancangan system

Perancangan sistem pada software arduino sangatlah penting sebab dari sinilah program dibuat dan diupload menggunakan software arduino, hal ini bertujuan untuk menyisipkan kode program kedalam arduino. Berikut adalah inisialisasi program arduino menggunakan arduino mega $2650 \mathrm{r} 3$.. Langkah ini bertujuan untuk memilih jenis dari mikrokontroller arduino yang akan digunakan untuk membuat sistem. Pada perancangan alat ini menggunakan arduino mega 2650. Selain langkah diatas kita juga perlu menginisialkan port serial tujuannya agar arduino dapat terhubung kekomputer biasanya menggunakan sebuah kabel USB agar arduino dapat tehubung dengan komputer. Penulisan kode program dilakukan untuk memberikan intruksi-intruksi menggunakan bahasa pemrograman $\mathrm{C}$ yang bertujuan untuk menjalankan sistem agar dapat bekerja sesuai kode program yang telah diisikan kedalam sebuah arduino, tanpa kode program sistem tidak dapat bekerja sebab kode program adalah bagian yang paling utama dalam kita membuat sebuah alat. Berikut adalah tampilan layer untuk mengisikan kode program pada software ide arduino di sajikan pada Gambar 6. 


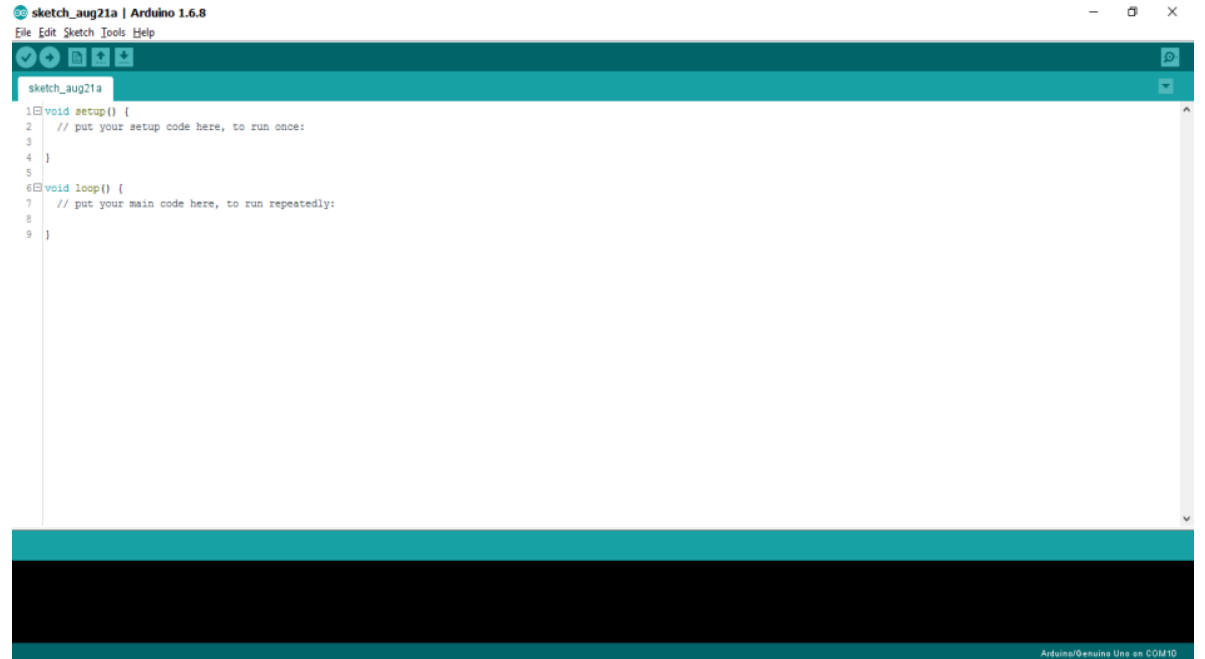

Gambar 6 Software Menulis Kode Program

Flowchart system

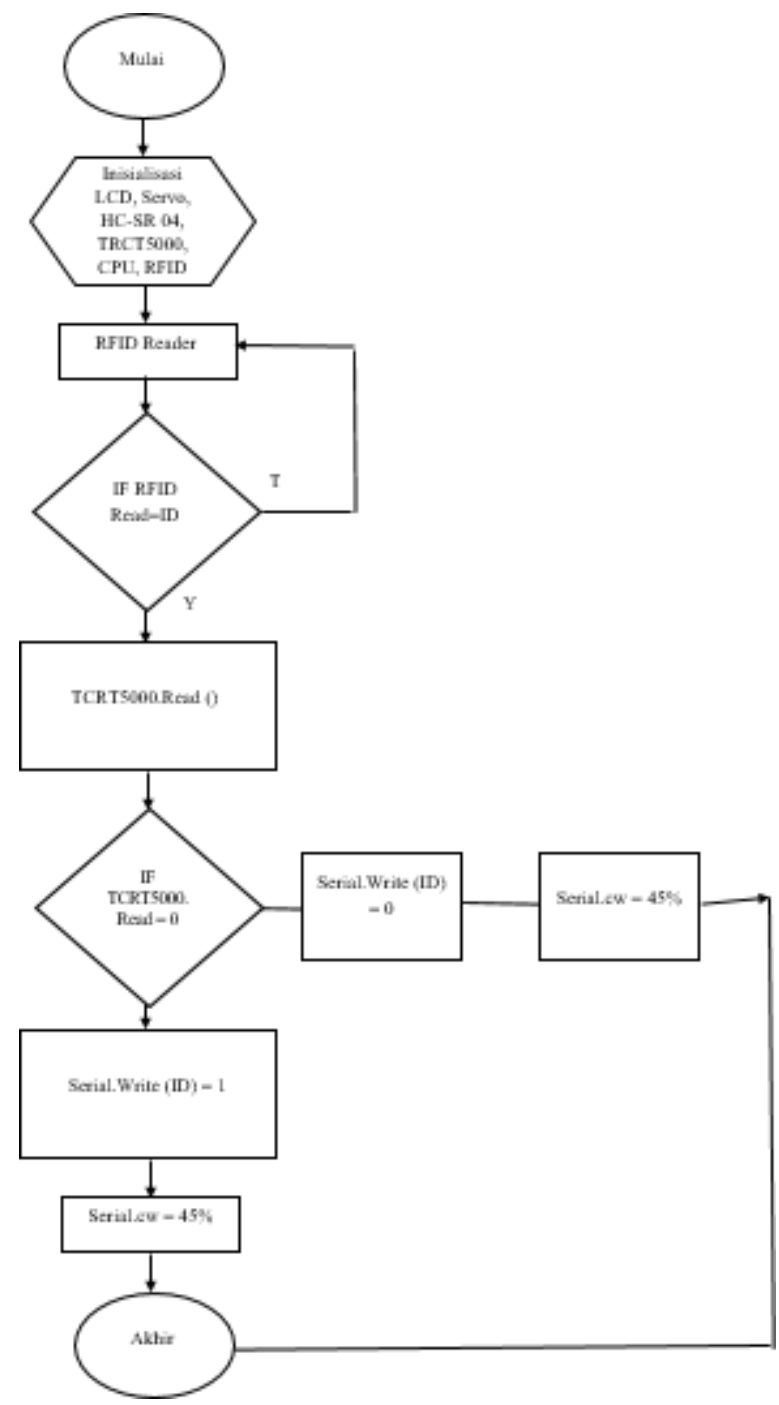

Gamar 7 Flowchart Sistem 


\section{HASIL DAN PEMBAHASAN (11 PT)}

Pada bagian ini akan dilakukan pembahasan hasil implementasi terhadap sistem yang telah dibuat apakah fungsi-fungsi yang telah dibuat dapat berjalan dengan baik dan benar sesuai hasil output yang diinginkan. Pada gambar 8 diperihatkan tampilan dari alat secara keseluruhan dari sisi samping dan bawah yang dapat terlihat jelas jumper atau pengkabelan, yang ada didalamnya 1 unit mikrokontroller, ir tret5000, project board, yang berdekatan dengan LCD dan HC-SR04, kemudian terlihat motor servo di mekanik untuk membuka dan menutup palang pintu parker.

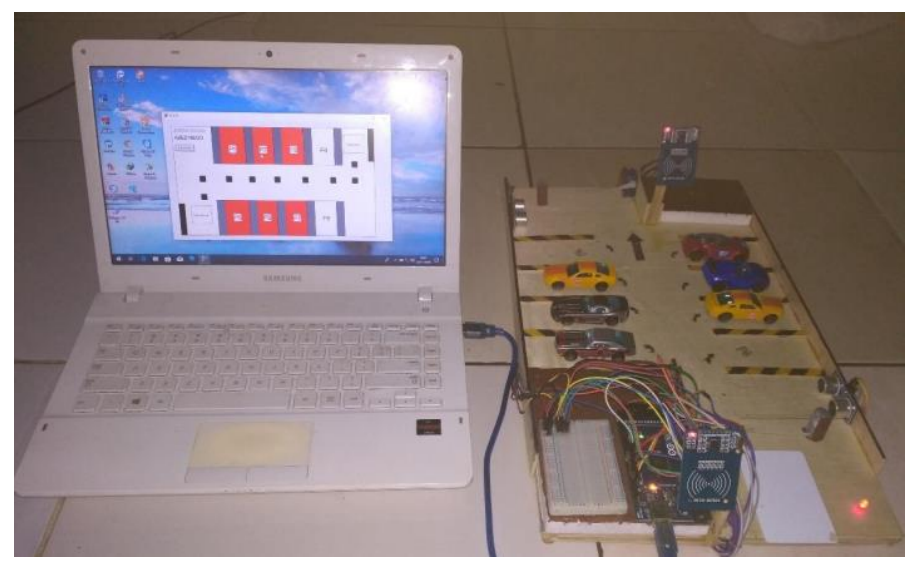

Gambar 8 Pengujian Alat

Penggunaan Sensor IR pada alat ini berguna sebagai pendeteksi benda yang berada pada lahan parkir karena Sensor IR ini difungsikan sebagai pendeteksi adanya kendaraan yang parkir pada lahan parkir. TCRT5000 salah satu sensor yang sering digunakan untuk sensor robot Line follower, keluaran dari sensor ini berupa sinyal analog, sehingga memungkinkan kita untuk menggunakan transistor untuk pengaplikasiannya, dalam TCRT5000 terdapat 4 pin yaitu VCC(Untuk input tegangan positif), GND(Untuk input tegangan negatif), D0(Digital Output), dan A0(Analog Output). Dalam sensor TCRT5000 terdapat 2 sensor infrared yang masingmasing berfungsi sebagai pemancar dan penerima, bentuknya seperti LED kecil, yang berwarna biru berfungsi sebagai pemancar cahaya, dan yang berwarna hitam berfungsi sebagai penerima cahayanya. Berikut adalah hasil dari pengujian Sensor Infrafed yang telah dipasangkan pada rangkaian alat ini sebagai berikut

Tabel 1 Hasil Pengujian Sensor

\begin{tabular}{|l|l|l|l|l|}
\hline No & Sensor IR & Kondisi & Status & Keterangan \\
\hline 1 & Sensor 1 & High & Kosong & Lahan Kosong \\
\hline 2 & Sensor 2 & High & Kosong & Lahan Kosong \\
\hline 3 & Sensor 3 & High & Kosong & Lahan Kosong \\
\hline 4 & Sensor 4 & High & Kosong & Lahan Kosong \\
\hline 5 & Sensor 5 & High & Kosong & Lahan Kosong \\
\hline 6 & Sensor 6 & Low & Penuh & Lahan Terisi Kendaraan \\
\hline 7 & Sensor 7 & High & Kosong & Lahan Kosong \\
\hline 8 & Sensor 8 & High & Kosong & Lahan Kosong \\
\hline
\end{tabular}

\section{V.SIMPULAN}

Berdasarkan hasil penelitian maka dapat disimpulkan bahwa cara kerja alat ini yaitu ketika ada kendaraan masuk akan menempelkan kartu identitas yang berbentuk tag atau id card ke rfid reader. Jika identitas dikenali maka palang pintu masuk yang berbentuk servo akan terbuka keposisi 900 lalu identitas dikenali akan terampil dilcd dan ketika kendaraan masuk akan mengenai sensor ultrasonic 
saat kondisi sensor tersebut $<=5$ akan menutup kembali palang pintu masuk keposisi 00. Ketika kendaraan sudah memasuki lahan parkir saat memilih posisi lokasi parkir akan mengenai sensor tcrt5000 yang berada disetiap lokasi lahan parkir dan akan menampilkan pesan penuh ketika posisi lahan sudah terisi, jika belum pesan akan terampil dilcd kosong. Ketika kendaraan akan keluar saat mengenai sensor ultrasonic2 akan diminta untuk memasukan id tag sebelumnya jika id sama maka pintu keluar servo2 akan terbuka keposisi 900 dan jika id tag tidak sama maka pintu tetap tertutup. Pada Sensor TCRT5000 terdapat 4 pin yaitu VCC(Untuk input tegangan positif), GND(Untuk input tegangan negatif), D0(Digital Output), dan A0(Analog Output). Dalam sensor TCRT5000 terdapat 2 sensor infrared yang masing-masing berfungsi sebagai pemancar dan penerima, bentuknya seperti LED kecil, yang berwarna biru berfungsi sebagai pemancar cahaya, dan yang berwarna hitam berfungsi sebagai penerima cahayanya.

\section{DAFTAR PUSTAKA}

[1] F. A. IMBIRI, N. TARYANA, and D. NATALIANA, "Implementasi Sistem Perparkiran Otomatis dengan Menentukan Posisi Parkir Berbasis RFId," ELKOMIKA J. Tek. Energi Elektr. Tek. Telekomun. Tek. Elektron., vol. 4, no. 1, p. 31, 2018, doi: 10.26760/elkomika.v4i1.31.

[2] I. A. Septriyaningrum, D. T. Nugrahadi, and I. Ridwan, "Perancangan Dan Pengembangan Prototype Sistem Parkir," Klik - Kumpul. J. Ilmu Komput., vol. 3, no. 2, p. 146, 2016, doi: 10.20527/klik.v3i2.59.

[3] У. Имени and А. И. П. Павлова, "ANALISA DAN PERANCANGAN SISTEM INFORMASI PARKIR DI UNIVERSITAS MURIA KUDUS,” vol. 3, no. 1, pp. 17-24, 2013.

[4] E. D. Widianto, H. M. Wijaya, and I. P. Windasari, "RFID Based Parking System and Vehicle Plate Number Image Recognition," J. Teknol. dan Sist. Komput., vol. 5, no. 3, pp. 115-122, 2017, doi: 10.14710/jtsiskom.5.3.2017.115-122.

[5] I. Winarsih and R. Mahendra, "Sistem Parkir Otomatis Menggunkan RFID Berbasiskan Mikrokontroler AT 89s51," J. Tek. Elektro JETri, vol. 8, no. 2, pp. 1-9, 2009.

[6] K. Pindrayana, R. Indra Borman, B. Prasetyo, and S. Samsugi, "Prototipe Pemandu Parkir Mobil Dengan Output Suara Manusia Mengunakan Mikrokontroler Arduino Uno," CIRCUIT J. Ilm. Pendidik. Tek. Elektro, vol. 2, no. 2, pp. 71-82, 2018, doi: 10.22373/crc.v2i2.3705.

[7] B. Kurniawan, E. B. Setiawan, and R. Hartono, "Perbaikan sistem parkir kendaraan bermotor di lingkungan universitas komputer indonesia dengan menggunakan rfid dan database," Maj. Ilm. UNIKOM, vol. 12, no. 2, pp. 125-134, 2015, doi: 10.34010/miu.v12i2.18.

[8] D. NATALIANA, I. SYAMSU, and G. GIANTARA, "Sistem Monitoring Parkir Mobil menggunakan Sensor Infrared berbasis RASPBERRY PI," ELKOMIKA J. Tek. Energi Elektr. Tek. Telekomun. Tek. Elektron., vol. 2, no. 1, p. 68, 2014, doi: 10.26760/elkomika.v2i1.68.

[9] S. Samsugi and A. Suwantoro, "Pemanfaatan Peltier dan Heater Sebagai Alat Pengontrol Suhu Air Pada Bak Penetasan Telur Ikan Gurame," pp. 295-299.

[10] R. Ridarmin, F. Fauzansyah, E. Elisawati, and E. Prasetyo, "Prototype Robot Line Follower Arduino Uno Menggunakan 4 Sensor Tcrt5000," I N F $O R M$ a T I $K a$, vol. 11, no. 2, p. 17, 2019, doi: 10.36723/juri.v11i2.183.

[11] A. S. Pramudyo, D. D. Kusuma, and H. Haryanto, "Rancang Bangun Graphical User Interface Untuk Pergerakan Motor Servo menggunakan Microsoft Visual Basic 2010 Express," Tek. Elektro, vol. 2, no. 2, p. 38, 2013.

[12] S. D. R. I Komang, "Rancang Bangun Sistem Pengunci Loker Otomatis Dengan Kendali Akses Menggunakan Rfid Dan Sim 800L," J. Ilm. Mhs. Kendali dan List., vol. 1, no. 1, pp. 33-41, 2020 . 